\title{
Thank You for Flying the Vomit Comet
}

Robert Dempsey, Johnson Space Center, Houston, TX

Gregory A. DiLisi, John Carroll University, University Heights, OH

Lori A. DiLisi, Parker Hannifin Corporation - Nichols Airborne Division, Elyria, OH

Gretchen Santo, Beaumont School for Girls, Cleveland Heights, OH

\section{Introductory Paragraph:}

This paper describes our flight aboard NASA's C9 “Weightless Wonder," more affectionately known as “The Vomit Comet." The C9 is NASA's aircraft that creates multiple periods of microgravity by conducting a series of parabolic maneuvers over the Gulf of Mexico.

\section{Key Words:}

- $\quad$ AAPT - American Association of Physics Teachers

- $\quad$ APS - American Physical Society

- $\quad$ Freefall

- Microgravity

- $\quad$ NASA - National Aeronautics and Space Administration

- Vomit Comet

- Zero-g

Physics and Astronomy Classification Scheme Numbers:

- $\quad$ 00.01.10.-m Announcements, news, and organizational activities

- $\quad$ 00.01.10.Cr Announcements, news, and awards

- $\quad$ 00.01.30.1a Secondary schools

- 00.01.55 General physics

- 00.01.50.My Demonstration experiments and apparatus

- $\quad$ 00.06.30.Gv Velocity, acceleration, and rotation 


\section{T-Minus 18 Months:}

To celebrate the 2005 World Year of Physics, AAPT, APS, and NASA co-sponsored a contest in which teams of high school students and their mentors could fly an experiment aboard NASA’s C9 “Vomit Comet." If selected, students would develop their experiment and travel to Houston to serve as the "ground crew" while the mentors would actually fly aboard the C9 to perform the experiment.

Our proposal explored how thin strands of liquid, suspended between two moveable supports, would handle the stresses of entering and exiting microgravity. To record the stability of these "liquid bridges," we would construct an apparatus that films the bridges while a 3-axis accelerometer records the motion of the C9. In January 2005, AAPT announced that our experiment was one of six proposals that had been selected to fly. Our experimental results have been posted at AAPT's website, http://www.xxx.org. Also, NASA's website, http://zerog.jsc.nasa.gov, has hundreds of photographs of our experience (under the "Student Campaign” link) while APS's website, http://www.physicscentral.com/freefall/index.html, gives a day-by-day account our adventure.

\section{T-Minus 8 Months:}

Our flight was scheduled for late-September 2005 and was coordinated by NASA's Reduced Gravity Program (RGP) out of Ellington Airfield, located ten minutes from Houston's Johnson Space Center. We were assigned a NASA mentor to help us meet the RGP's experimental hardware constraints as well as navigate us past the mountain of paperwork required for flight aboard the C9. Each flyer was then required to be certified "flight-ready" by submitting to an FAA flight-physical, the same head-to-toe exam pilots undergo that places heavy emphasis on visual acuity. 
Through the summer of 2005, we constructed our experimental apparatus. Our device was simple in concept but grew in complexity as we attempted to meet NASA's requirements for flight-worthy hardware. Every piece of equipment that flies aboard the C9 must be described in a “Test Equipment Data Package” (TEDP), a comprehensive report of the hardware's safety qualifications and ability to withstand a catastrophic 9-g crash of the C9 without injuring the flight-crew or passengers. Specification sheets for every nut and bolt of hardware must be submitted. Even for a simple off-the-shelf mounting bracket, we had to supply NASA with the bracket's dimensions, tolerances, operating temperature, impact strength, etc. The entire apparatus must then be described in terms of its electrical power consumption, flammability, laser usage, operational pressure range, etc. Our TEDP was re-submitted a dozen times before the actual flight.

As our flight week of September 21-30 arrived, so too did hurricane Rita. Our flight was scheduled for the exact day that Rita slammed into Houston and forced the first and only shut down of Mission Control while Americans were in space. Like many NASA flights, ours was postponed several times. We were eventually rescheduled for May 2006.

\section{T-Minus One Week:}

The additional eight months of time allowed us to improve our hardware and rehearse the procedures needed to perform the in-flight experiment. Most notably, we automated most of our experimental procedures. Because head-movement is the leading cause of motion sickness while flying aboard the C9, automating our apparatus helped keep our team members from becoming victims of the "Vomit Comet." When our rescheduled flight week of May 3-12 finally arrived, we shipped our improved apparatus to Ellington and headed for the now calm waters of the Gulf of Mexico. 


\section{Flight Week:}

Our first two days at Ellington were spent in physiological training courses culminating in a ground-based altitude chamber test that simulated atmospheric conditions at 25,000 $\mathrm{ft}$. The purpose of this simulation was to see how each flyer would react to hypoxia if the C9 experienced a rapid decompression during flight. After hours of coursework, we started the chamber test by donning fighter-pilot’s masks and “denitrogenizing” our bodies by breathing pressurized oxygen for thirty minutes. Once we were denitrogenized, the chamber simulated an ascent to 25,000 $\mathrm{ft}$ at a rate of 5,000 ft per minute. During this ascent, the gas in everyone's intestinal tract expanded to three times its normal volume. At some time, everyone in the chamber had to release this gas, which we were encouraged to do as often as possible. Luckily we were wearing oxygen masks for most of the simulation. Once at 25,000 ft, half of us were asked to remove our oxygen masks for five minutes while the other half noted our response to hypoxia. When I removed my mask, I felt no symptoms of hypoxia for the first three minutes. At three minutes, as shown in Figure 1, my head began to throb and I couldn't perform basic tasks. NASA personnel inside the chamber (who thankfully keep their masks on) distributed a $5^{\text {th }}$ grade-level quiz to test our brain function. I was able to spell my last name but could only remember three of the past five presidents. Some people in the chamber became giddy and just laughed uncontrollably for the remaining two minutes. One gentleman simply sat with a blank gaze. He never responded to various instructions and eventually had to be helped back into his mask. At four minutes, my peripheral vision was totally gone. By five minutes, I was unable to write and was beginning to black-out. Once everyone was back on oxygen, the chamber simulated a descent to ground at a rate of 2,000 ft per minute. Following the chamber flight, NASA had a little surprise waiting for us --- we were secretly filmed during the chamber test. 
We all gathered to watch the reaction of various participants and were shocked to learn that everyone thought they acted normally until they saw themselves on film.

We spent the next day preparing for and undergoing our team’s “Test Readiness Review” (TRR). During the TRR, a group of roughly ten stern-faced NASA personnel (scientists, pilots, and flight surgeons) inspected every piece of experimental hardware flying aboard the C9. To get an idea of what a TRR is, imagine a giant science fair occurring in a $120^{\circ} \mathrm{F}$ airplane hangar underneath the wings of the C9. Each apparatus was setup on a table and surrounded by the high school students and mentors. The NASA personnel moved from table-to-table demanding that each apparatus be modified in some way to guarantee flight safety, then revisited a few tables to see how the modifications were progressing. Figure 2 shows a nervous moment during our TRR while Figure 3 shows the joyous moment when our apparatus was "officially certified for flight" and loaded aboard the C9.

\section{Our Flight:}

After 18 months of preparation, the day of our flight finally arrived. The C9 was scheduled to take-off at 10:00 am. At 9:00 am, a flight surgeon administered a "cocktail” of SCOP-DEX to each member of our flight crew. SCOP-DEX is a combination of Scopolamine and Dexedrine tablets given to help with motion sickness. Historically, 60\% of first-time flyers aboard the C9 experience significant motion sickness, including nausea and vomiting; however, when using the recommended dosage of SCOP-DEX, this motion sickness rate drops to $15 \%$ or less. Finally, each member donned an olive-colored flight-suit, complete with a highly-coveted personalized name-patch and multiple plastic "barf-bags" on the chest and legs. To avoid any messy surprises during microgravity, a thorough tutorial on proper vomiting techniques was given, and twice reviewed, in the half-hour before flight. 
After takeoff, the C9 quickly reached 25,000 $\mathrm{ft}$ and the crew gave us the okay to leave our seats and prepare our experiment which had been locked-down for takeoff. The interior of the C9 is the size of a typical DC-9 aircraft --- I'm 5'8' and could easily reach the ceiling of the C9 with both arms outstretched. The striking feature of the interior is that with the exception of a few seats at the rear of the aircraft, where we sat for takeoff and landing, the entire aircraft is void of seats. Instead, the interior is covered by a shiny, white, two-inch-thick foam padding brilliantly illuminated by two banks of overhead lights that run the entire length of the aircraft. Every ten feet, an experimental apparatus is bolted to the floor. As shown in Figure 4, Velcro belts are also located in front of each apparatus so that experimenters can secure themselves during moments of zero-g.

The C9 then climbed from $25,000 \mathrm{ft}$ to $35,000 \mathrm{ft}$ at a $45^{\circ}$ ascent angle. This ascent, shown in Figure 5, only took $\sim 25$ seconds during which time we experienced a 2-g force towards the floor. The C9's trajectory is designed such that all g-forces are normal to the floor with almost no variations occurring in other directions. I remember the eerie sensation of my flight-suit being pulled to the floor and feeling like it was a very heavy liquid being poured over my body. When the C9 reached the top of each parabola, a crew member screamed out, "Over the Top!" As the C9 angled $45^{\circ}$ down, also shown in Figure 5, and returned to the 25,000 ft altitude, we experienced the $\sim 25$ second interval of microgravity. At the bottom of each parabola, as the C9 pulled out of its nosedive and into another $45^{\circ}$ ascent, the crew member then screamed, "Feet Down," which was our warning that the 2-g forces would soon hit us. We had perhaps two seconds to orient our feet to the floor before the oppressing 2-gs kicked back on. This cycle repeated 42 times: the flight plan called for ten parabolas out of Houston to Mexico; a fiveminute turn; ten parabolas back to Houston; another five-minute turn; ten parabolas back to 
Mexico; a final turn; then ten parabolas back to Houston. After these 40 parabolas, we were treated to a single parabola simulating lunar gravity, then a final parabola simulating Martian gravity. Each flight lasted two hours from takeoff to landing with the 42 parabolas lasting only about an hour. Each team was given two days of flight for a total of 84 parabolas.

During the ascent portion of each parabola, I mostly recall hearing the C9's engines straining to climb. As the C9 went "over the top" and through its descent, the sounds of the straining engines were replaced with the stark silence of idle engines. Strangely, one can anticipate the periods of microgravity by listening to the plane. The silence was then quickly interrupted by the happy (usually) outbursts of the flyers. During periods of microgravity, I was completely free to bounce around the interior of the C9 --- the slightest touch of a wall sent me spinning and bouncing against the padded surfaces, perhaps the best demonstration of Newton's Laws of Motion one can imagine. If you've ever ridden a roller coaster, you've experienced that brief exhilarating instant as the coaster goes "over the top" of the first hill and you feel that split instant of microgravity. If you're like me, your body just instinctively craves for gravity to kick in, at the bottom of the hill. Aboard the C9, that feeling of going "over the top" lasts for 25 seconds. You need a few parabolas to get accustomed to prolonged feeling of exhilaration and to realizing that gravity isn’t immediately returning.

NASA hopes that each flight of the C9 is a "No Kill” flight, meaning that no one on-board vomits. Though no one on our team vomited, neither of our two flights were “No Kill.” On each flight, 2-3 flyers became sick enough that they vomited and had to leave the experimental area and return to their seats at the back of the plane. Each flight had at least one flyer who vomited during all 42 parabolas. NASA emphasized that conflicting sensory signals to the brain are the most common cause of nausea and that no factors predict who will get sick during flight. We 
were encouraged not to move our heads too rapidly, not to look out the window at the horizon (feeling weightless while seeing a vertical horizon certainly will send confusing sensory feedback to the brain), and not to try any overly-ambitious gymnastic feats. For whatever reason, everyone on our team seemed to do very well in microgravity and we were all able to enjoy a few parabolas of somersaults, handstands and Superman-stunts as shown in Figure 6. One memorable moment was taking several self-portraits by activating the timer on my digital camera and aiming it at me while the camera floated in zero-g. NASA graciously provided onboard photographers and videographers to preserve our experience on DVD.

\section{Acknowledgements:}

The authors wish to acknowledge our student "ground crew," chaperones and various personnel for their hard work and expertise over the past 18 months: Carrie Blakeley, Doug Blakeley, Adam Cain, Carmela DiLisi, Anna Faist, Jennifer Haag, Rachel Hubbard, Emily Infeld, Grace Kozan, Suzanne Maloney, Laura Manson, Bridget McMurray, Anna Mohr, Leslie Okeson, Mary Ryan, and Larry Stevanus. We also acknowledge the scores of individuals from AAPT, APS and NASA's RGP who made this experience possible --- we cannot mention everyone by name, but the entire staff couldn't have been more generous or more professional to our team 
Figure 1:

Altitude Chamber Flight

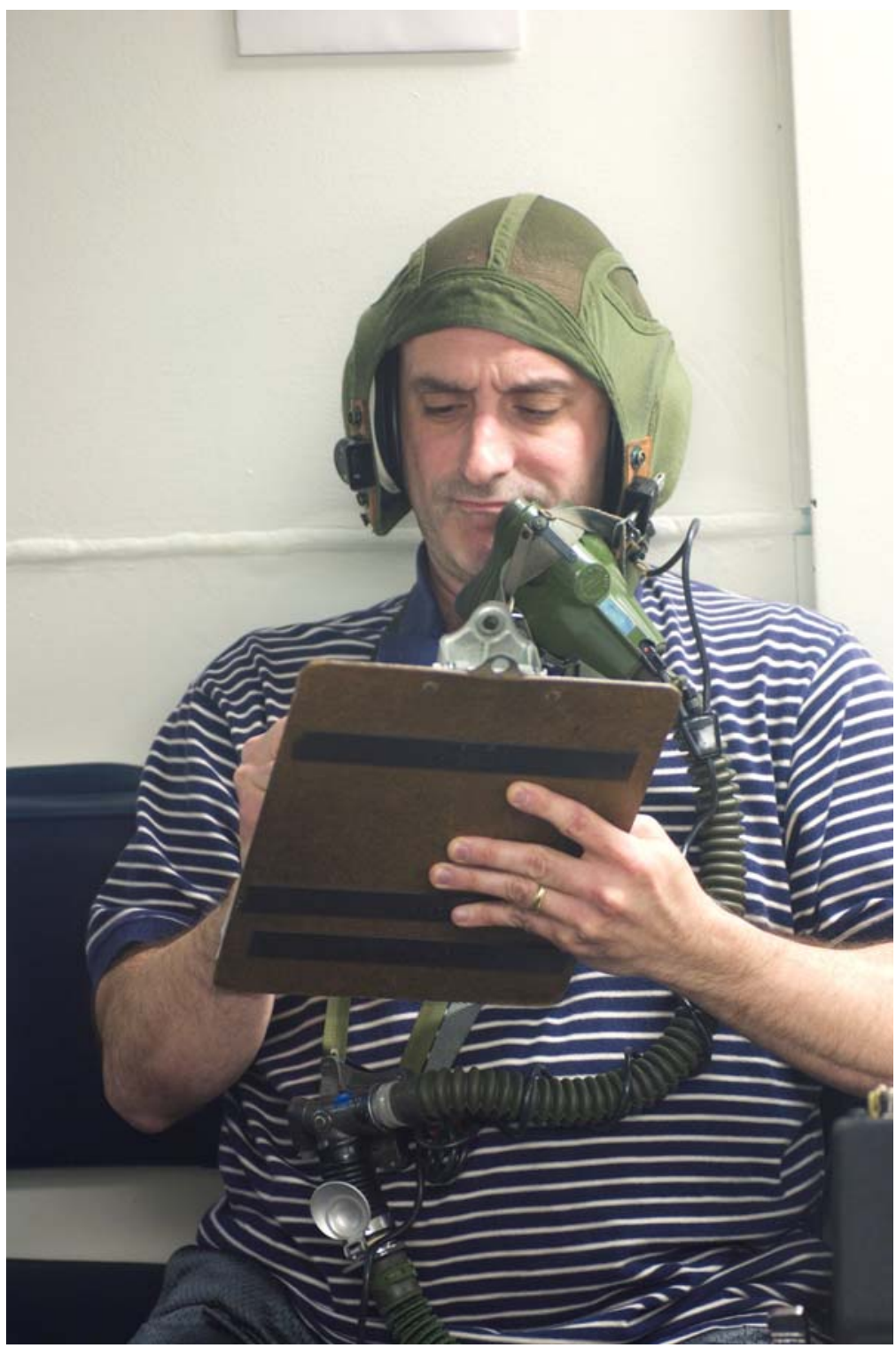


Figure 2:

Test Readiness Review (TRR) in Progress
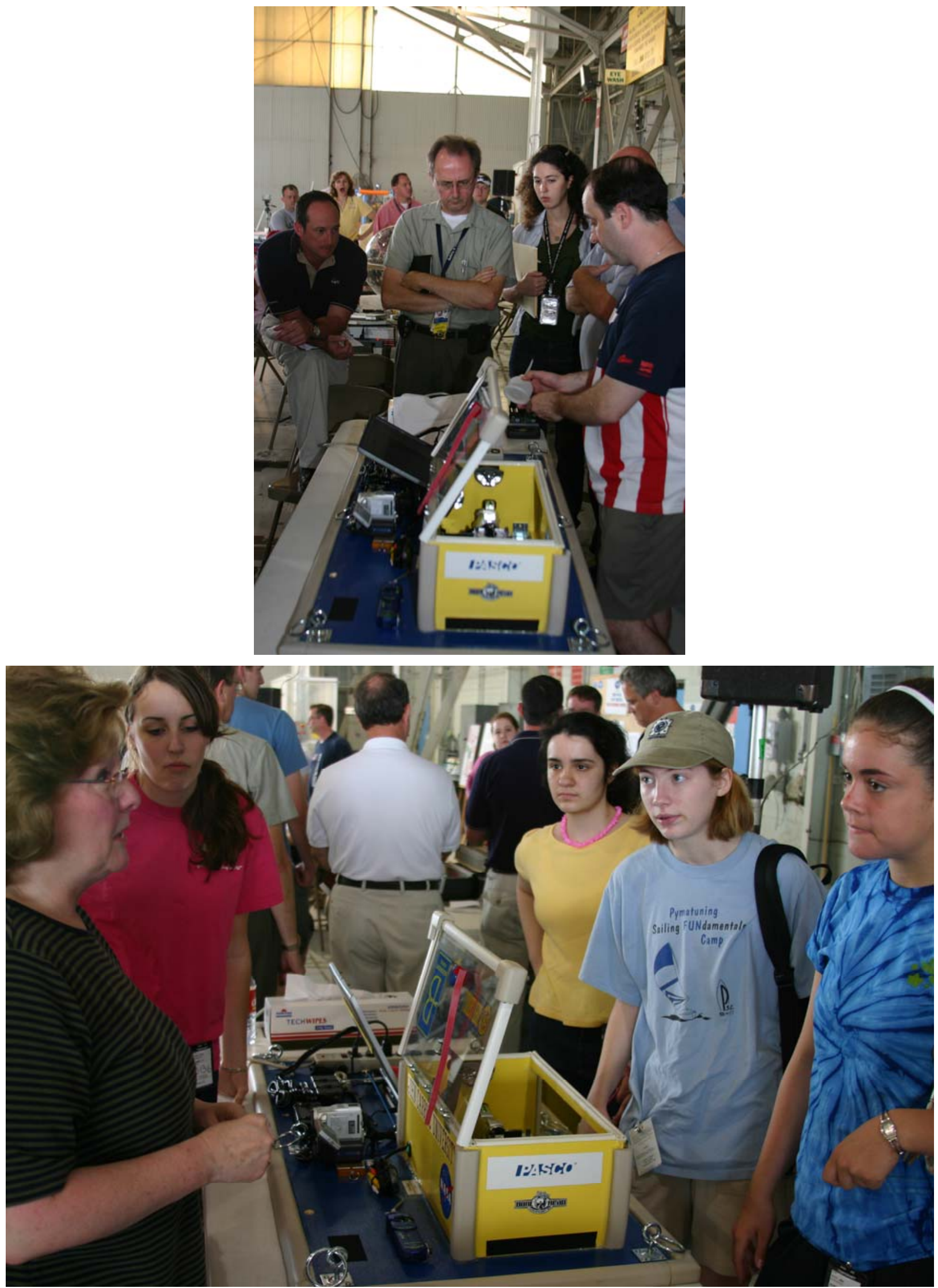
Figure 3:

Loading the Experiment
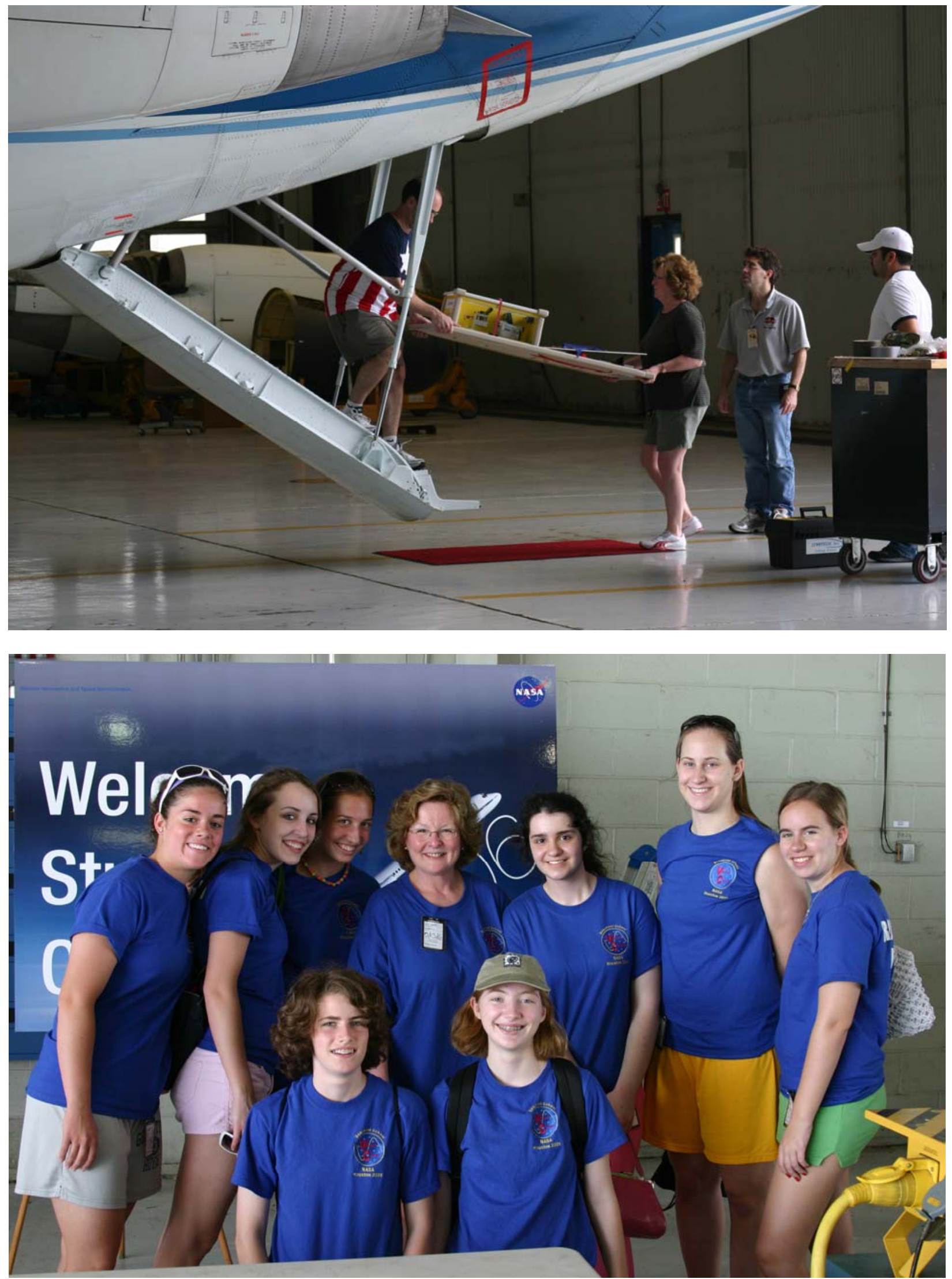


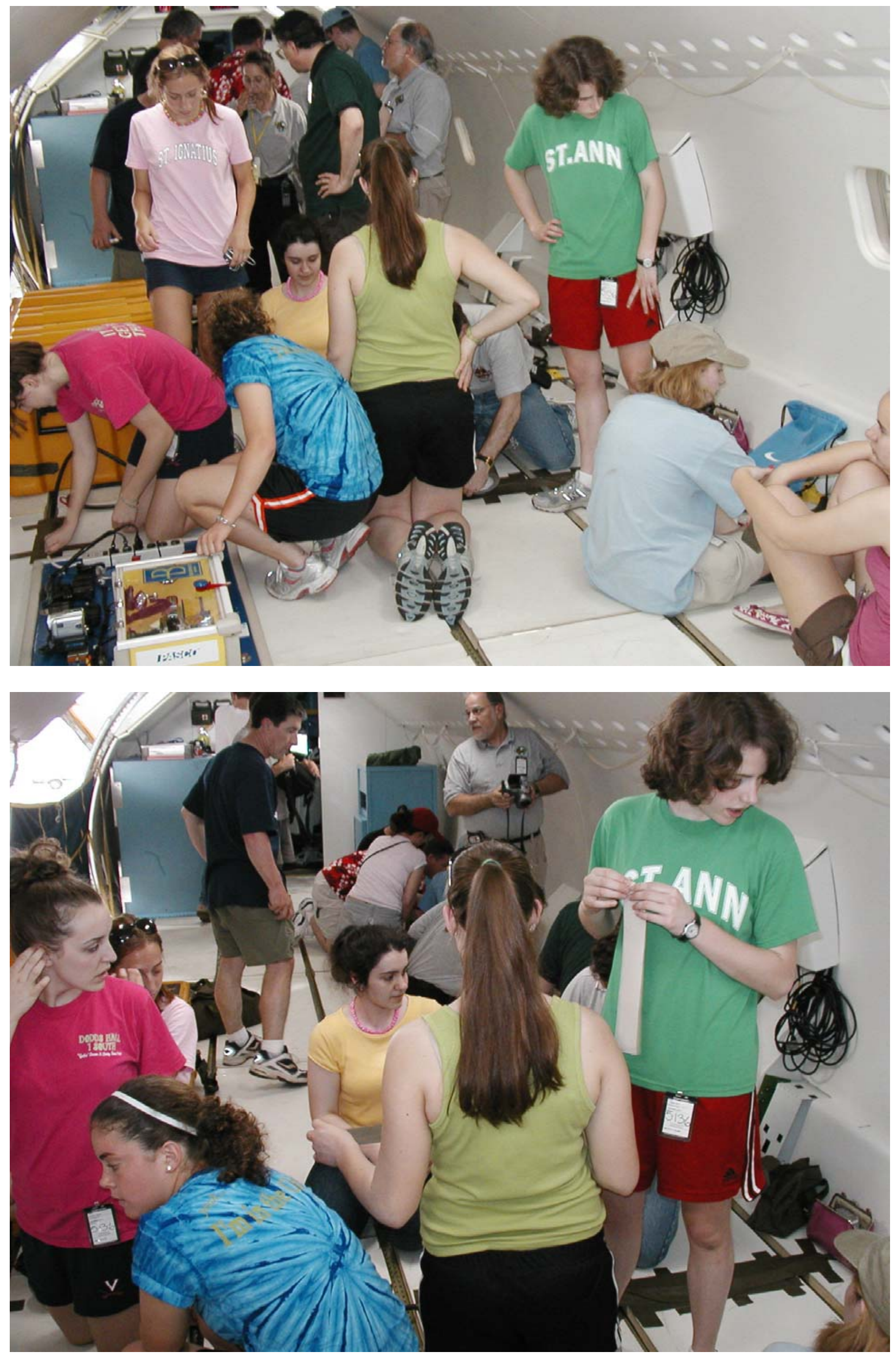


Figure 4:

Working aboard the C9
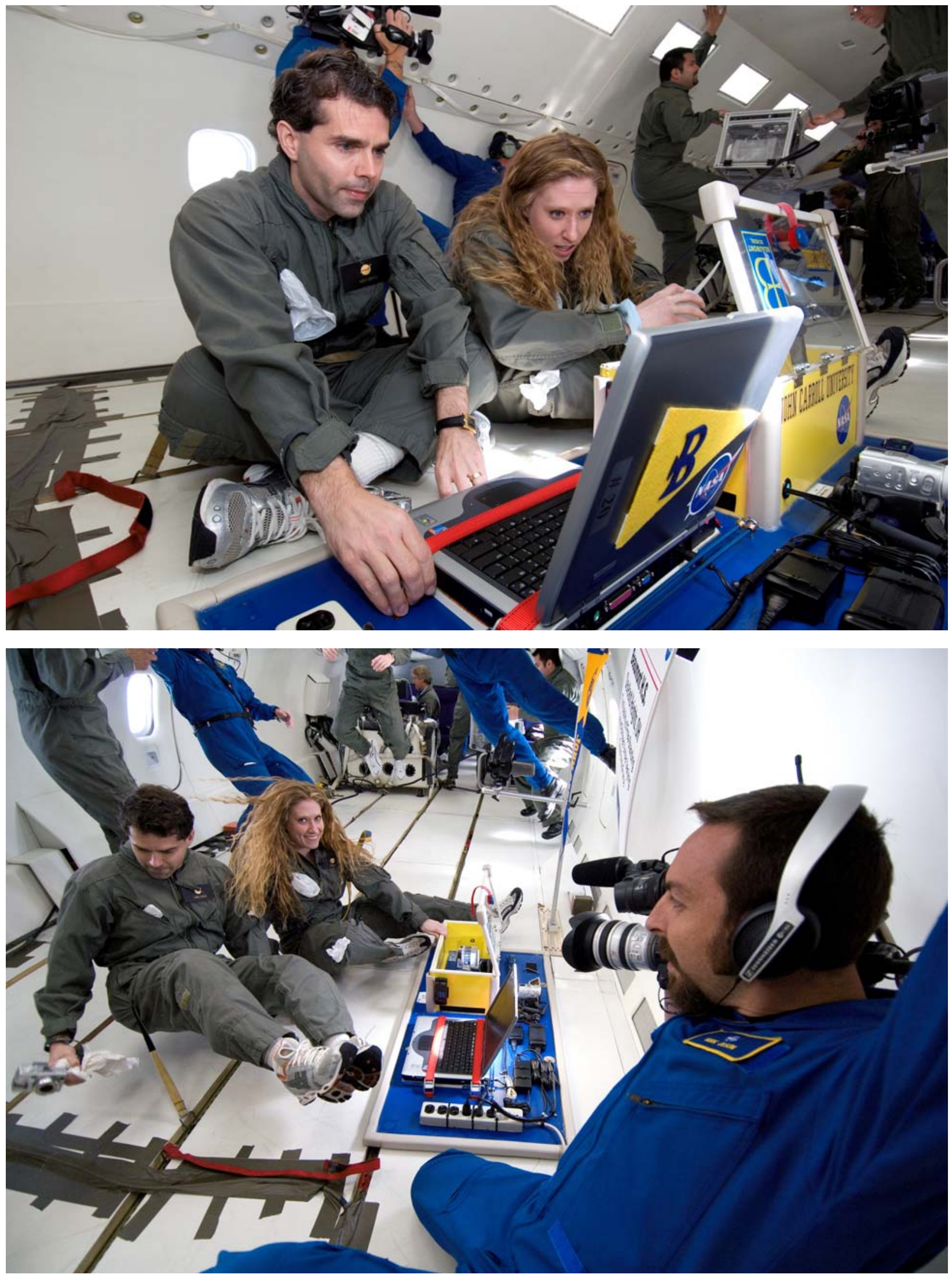
Figure 5:

The C9's Flight Trajectory
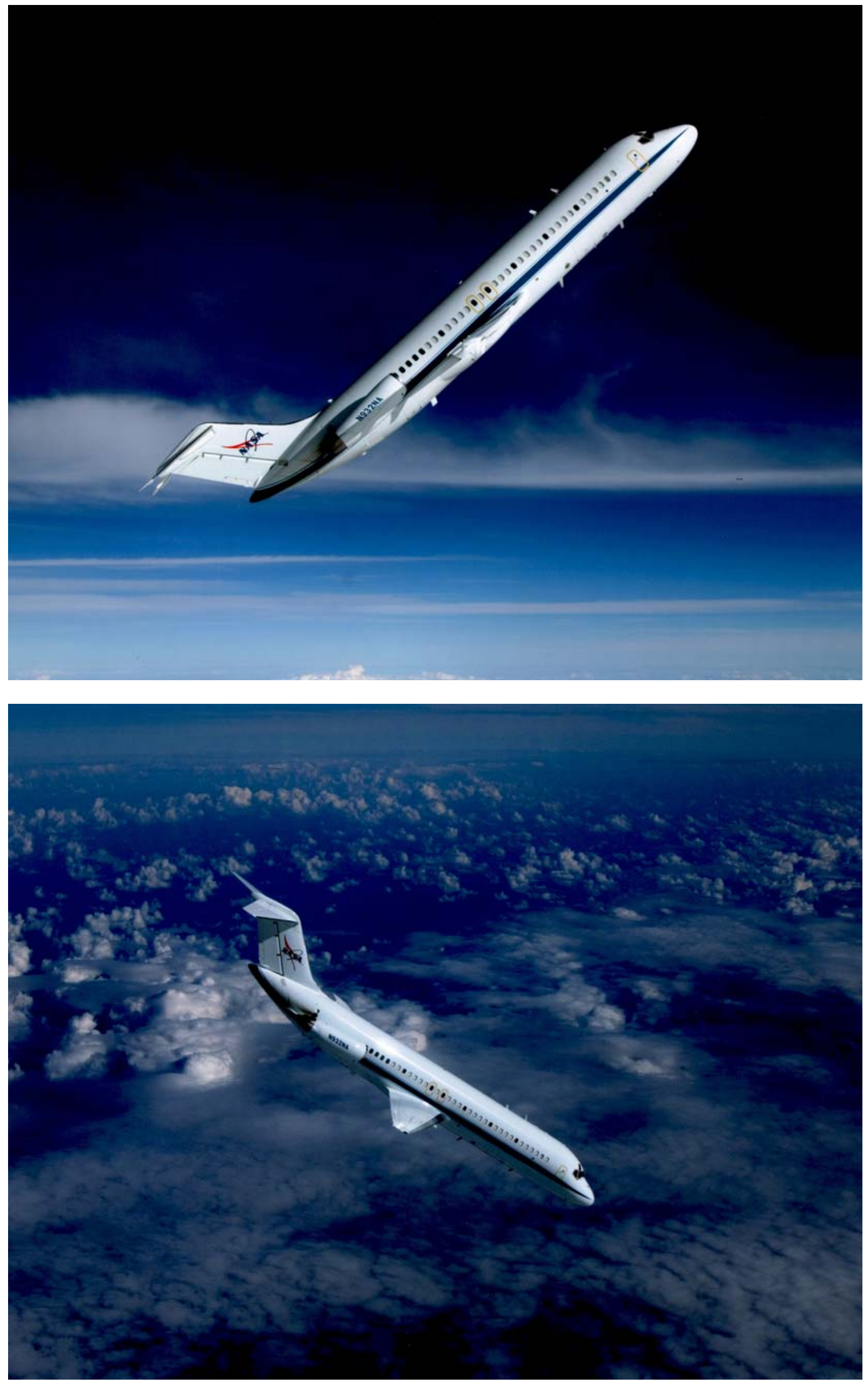


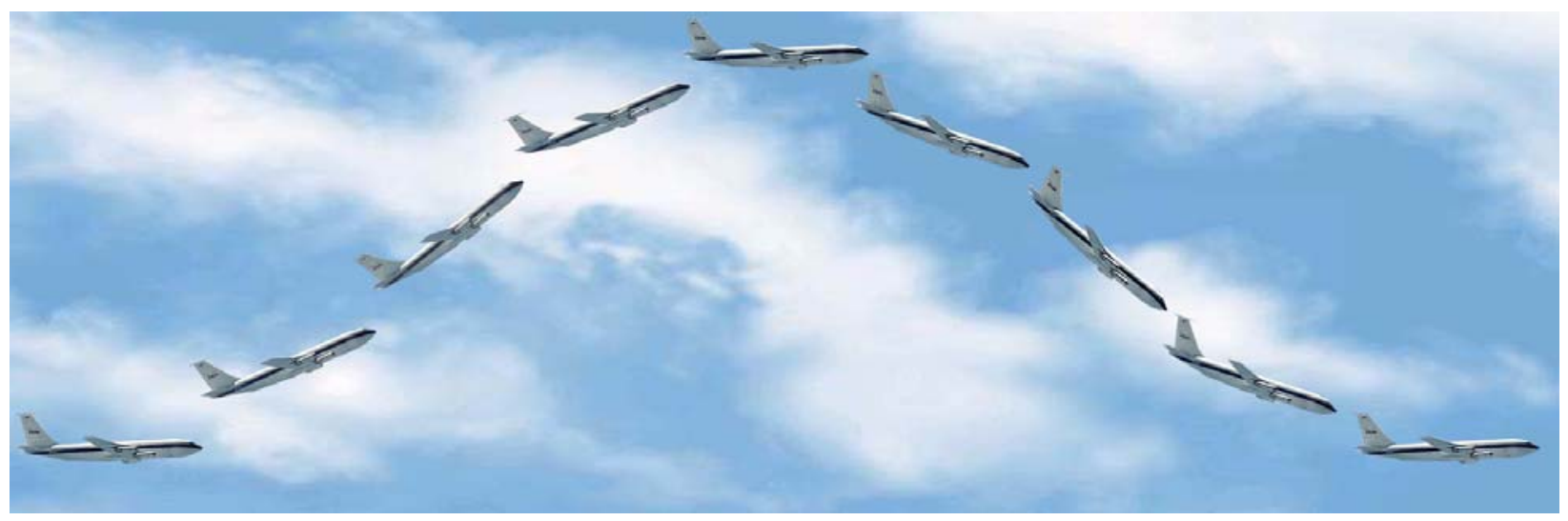


Figure 6:

Playing Aboard the C9
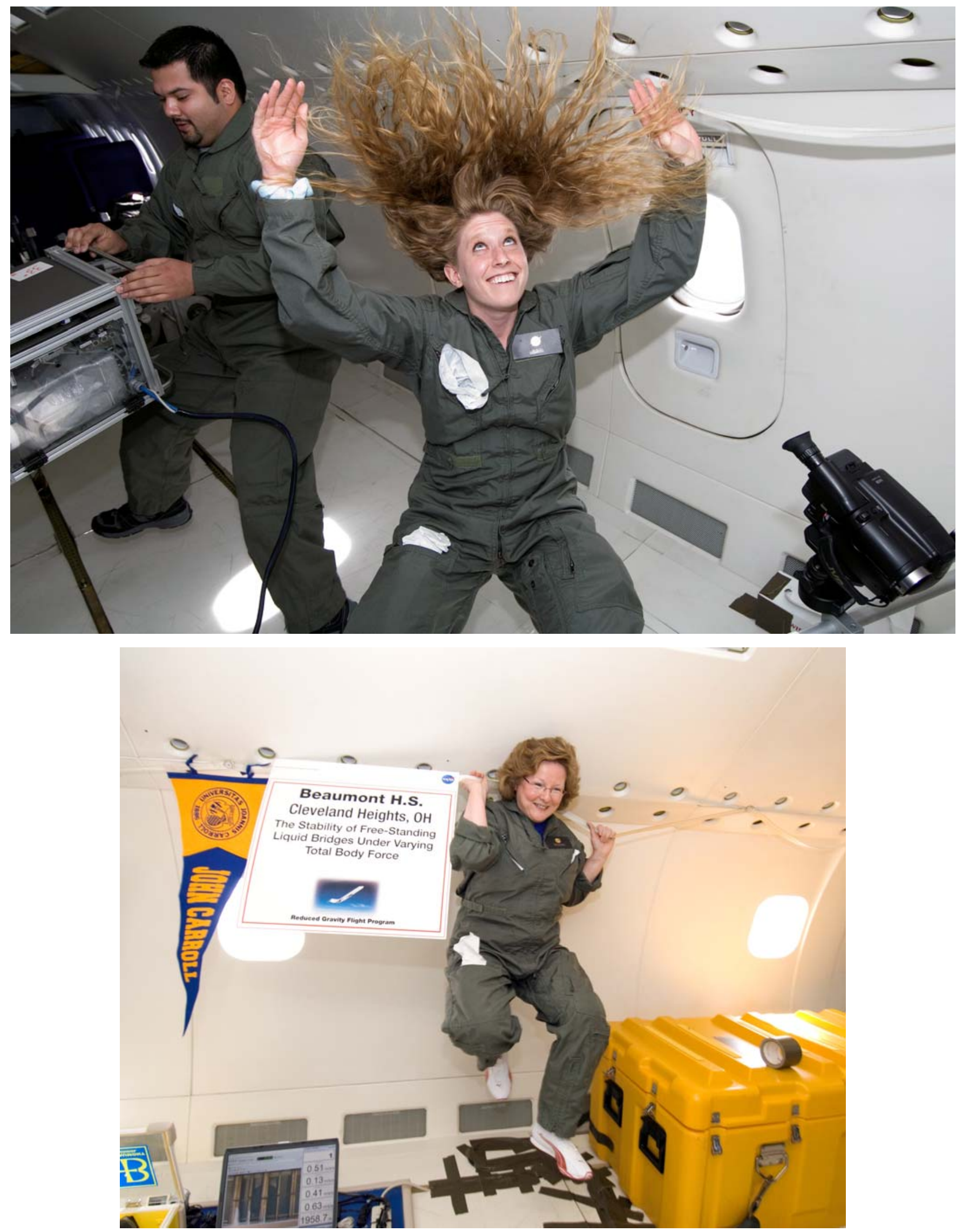


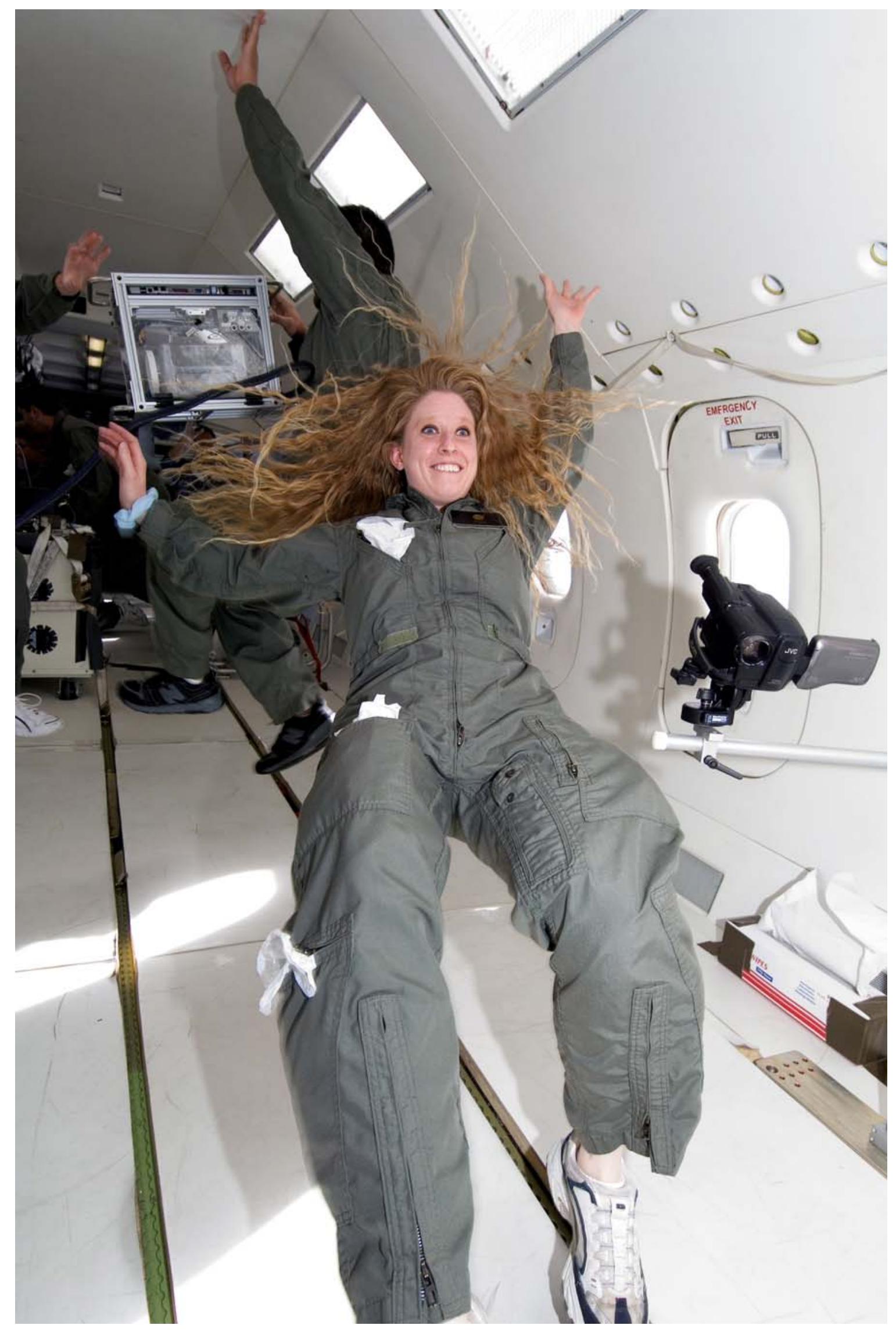



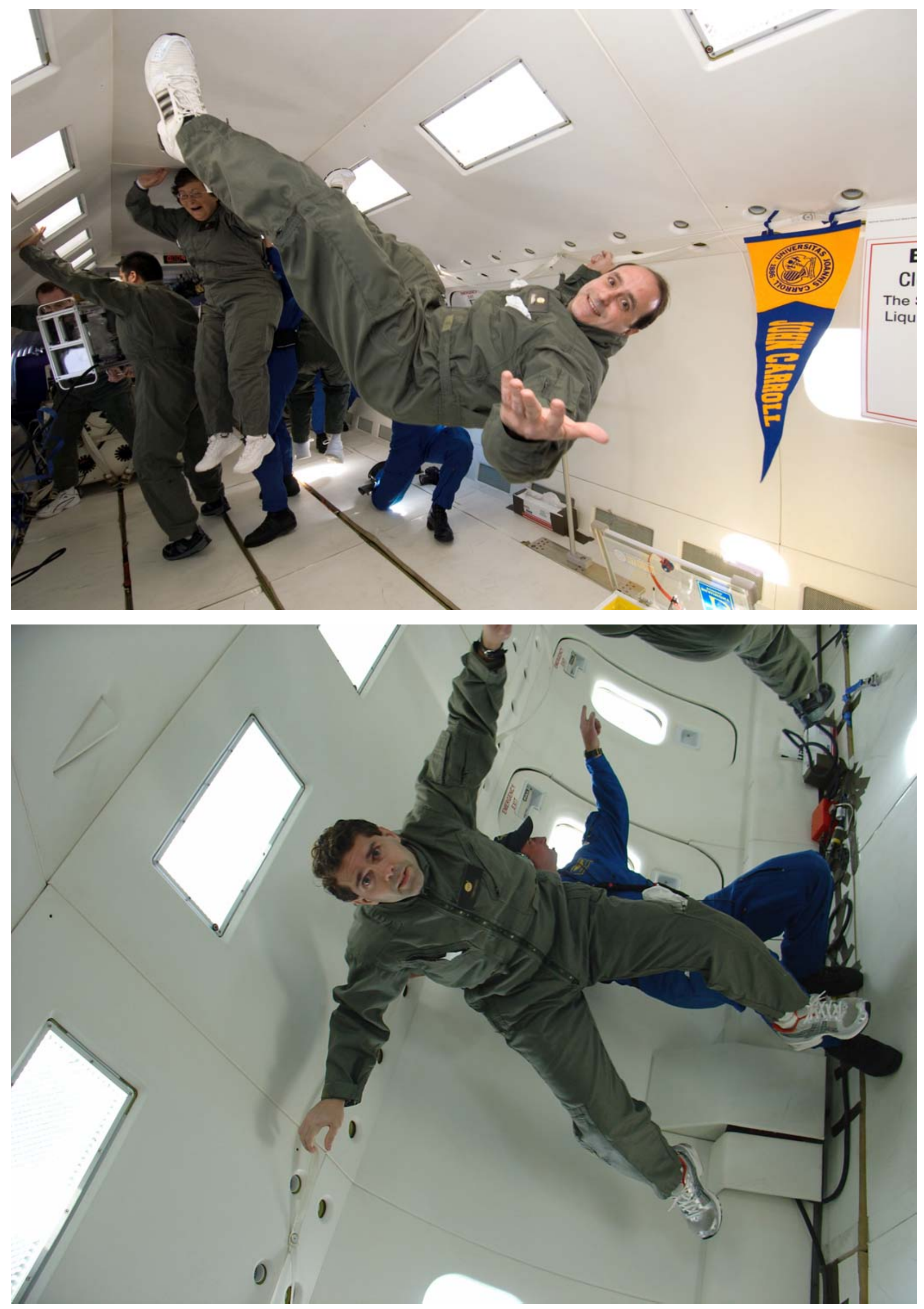


\section{Biographical Information:}

Robert Dempsey received his B.S. from the University of Michigan in astronomy and physics and his Ph.D. from the University of Toledo. He is currently a Johnson Space Center flight controller for the International Space Station where he has received numerous NASA awards including citations for his service during on-orbit crises and recovery.

NASA/Johnson Space Center - DF25, Houston, TX 77058

Gregory A. DiLisi received his B.S. from Cornell University in applied and engineering physics and his Ph.D. from Case Western Reserve University in experimental physics. He is currently an Assistant Professor of Science Education at John Carroll University where he teaches physics, science methods, and instructional technology courses.

20700 North Park Blvd., University Heights, Ohio 44118; gdilisi@jcu.edu

Lori A. DiLisi received her B.S. in aerospace engineering and M.S. in fluid and thermal sciences from Case Western Reserve University. Her graduate work focused on the spread of flames across pools of alcohol. She now works for the Parker Hannifin Corporation's Nichols Airborne Division where she designs fuel pumps for aircrafts and missiles.

711 Taylor Street, Elyria, Ohio 44035, USA

Gretchen Santo received her B.S. from the University of Dayton and is currently the Science Department chair at Beaumont High School for Girls. For the last twenty years, she has been teaching life science courses and currently teaches senior-level biology courses and laboratories. 3301 North Park Blvd., Cleveland Heights, Ohio 44118, USA 